\title{
Posterior Reversible Encephalopathy Syndrome: An Expanding Phenotype
}

\author{
Vrajesh Udani
}

\begin{abstract}
Keywords: Adolescent and children, India, Posterior reversible encephalopathy syndrome.
\end{abstract}
Indian Journal of Critical Care Medicine (2020): 10.5005/jp-journals-10071-23696

The term "hypertensive encephalopathy" has been used for several decades describing an acute neurological syndrome associated with severe hypertension. With the advent of magnetic resonance imaging (MRI), it became clear that reversible edema mostly in the posterior brain regions appeared to underlie these symptoms. It also became clear that hypertension may be absent in about a fifth of cases. ${ }^{1,2}$ In 1996, Hinchey et al. described the disorder, now known as "posterior reversible encephalopathy syndrome" (PRES), in a study of 15 patients. ${ }^{3}$

This is primarily a disease of young adults though it has been described over the entire lifespan. In general pediatric admissions, PRES appears rare with a rough estimate of only $0.04 \%$ in a large US survey of a countrywide in-patient database. ${ }^{4}$ Higher prevalence rates are noted in retrospective studies in pediatric intensive care unit (PICU) patients $(0.4 \%)^{5}$, oncology centers $(0.7 \%)$, and transplant centers (up to $5.2 \%$ ). ${ }^{2}$ Hypertension appears to be the most common risk factor and is present in $\sim 80-85 \%$; other common risk factors include renal, hemato-oncological and autoimmune disorders, immunosuppressive/cytotoxic drug use, bone marrow/organ transplantation, and others. ${ }^{2}$

Two pathophysiological mechanisms are implicated. The first purports that rapidly developing hypertension exceeds the upper limit of cerebral autoregulation with resultant hyperperfusion, blood-brain barrier disruption, and vasogenic edema. The second emphasizes a primary vascular endothelial dysfunction caused by cytotoxic/immunosuppressive agents or excessive circulatory cytokines leading to fluid extravasation into the interstitium and vasogenic edema. Recently, the central role of vascular endothelial growth factor (VEGF), an angiogenic factor secreted by the endothelium that increases vascular permeability, has been highlighted. ${ }^{1,2}$

Adolescent onset is most common and seizures are seen initially in almost $80-90 \%$, much more than in adults. ${ }^{2}$ Other symptoms include varying degrees of encephalopathy, visual disturbances, and headaches and less commonly focal neurologic deficits. These symptoms peak at 12-48 hours and usually recover in a few days to weeks.

Characteristic MRI patterns are bilateral, asymmetric subcortical T2 hyperintensities, without diffusion restriction or contrast enhancement in (1) posterior parieto-occipital regions, (2) holo-hemispheric watershed areas, and (3) around the superior frontal sulci. ${ }^{1}$ Atypical lesions in the frontal/temporal lobes are particularly common in children ${ }^{2}$ and may be isolated. Corpus callosal, cerebellar, brainstem, and basal ganglia lesions may pose a diagnostic challenge. Other atypical features include restricted diffusion indicating ischemic cytotoxic edema, or even frank infarction, hemorrhagic lesions, and contrast enhancement.
Department of Child Neurology, PD Hinduja Hospital and Medical Research Centre, Mumbai, Maharashtra, India

Corresponding Author: Vrajesh Udani, Department of Child Neurology, PD Hinduja Hospital and Medical Research Centre, Mumbai, Maharashtra, India, Phone: +919820964216, e-mail: vrajesh. udani@gmail.com

How to cite this article: Udani V. Posterior Reversible Encephalopathy Syndrome: An Expanding Phenotype. Indian J Crit Care Med 2020;24(12):1163-1164.

Source of support: Nil

Conflict of interest: None

Susceptibility-weighted imaging (SWI) has demonstrated a high number of cerebral microbleeds.

As one can see, clinical and imaging features are relatively nonspecific and many conditions like acute disseminated encephalomyelitis (ADEM), infectious encephalitis, venous infarcts, osmotic demyelination, and other conditions may mimic PRES. These diagnostic pitfalls can be avoided if one has a high degree of suspicion while dealing with patients with underlying risk factors, especially hypertension. However, the latter often gets overlooked in children and even if diagnosed, may be passed off as reactive to seizures, anxiety, etc. To confound the picture the mean blood pressure in PRES is often only modestly increased and may be normal or even low.

The article in this month's IJCCM by Behera et al. is an important addition to the Indian experience. ${ }^{6}$ They retrospectively studied PRES in the PICU over a period of 3 years. Of 1,925 admissions, they identified 16 patients with PRES, which constituted $0.25 \%$ of all admissions - a figure similar to a US study of PICU patients. ${ }^{5}$ Three criteria - acute neurological symptoms, imaging evidence of vasogenic edema in bilateral posterior regions, and evidence of clinical and imaging reversibility, formed the basis of PRES diagnosis. Definitions of PRES vary in the several published retrospective studies with some using a narrow definition as the one used here and others less restrictive criteria. The former may include more typical mild-moderate cases while the latter would include many more atypical presentations as well as severe cases.

The male preponderance in this study is contrary to the western experience, ${ }^{1,4}$ where females predominate, and this warrants an explanation. One possibility is that it might be due to the male child bias in health-seeking behavior, which has been reported from the same city. ${ }^{7}$ Risk factors for PRES were similar to published literature, especially hypertension. Interestingly, anemia was almost universal and was considered a risk factor by the authors. This is similar to a US PICU study of 10 patients where the prevalence of anemia

(c) The Author(s). 2020 Open Access This article is distributed under the terms of the Creative Commons Attribution 4.0 International License (https://creativecommons. org/licenses/by-nc/4.0/), which permits unrestricted use, distribution, and non-commercial reproduction in any medium, provided you give appropriate credit to the original author(s) and the source, provide a link to the Creative Commons license, and indicate if changes were made. The Creative Commons Public Domain Dedication waiver (http://creativecommons.org/publicdomain/zero/1.0/) applies to the data made available in this article, unless otherwise stated. 
in PRES patients was significantly higher than in non-PRES PICU controls. ${ }^{5}$ The present study could not confirm this finding, as they did not use any control group. In a large pan-US survey ${ }^{4}$, though anemia was a significant risk factor in the univariate analysis, it lost its significance after adjusting for other cofactors. Further studies would be needed to settle this question.

The outcomes in this study were particularly good, possibly partly because clinical/imaging reversibility was part of the inclusion criteria. Though most studies also report a good prognosis, there have been increasing reports of morbidity and less frequent mortality, possibly related to delayed diagnosis, and suboptimal management. Atypical imaging features like restricted diffusion and hemorrhages portend such outcomes. Interestingly despite these atypical imaging features being not uncommon in this study, the outcome remained good, suggesting the need for re-evaluation of the prognostic significance of these factors.

The main limitations of all studies done in PRES are (1) most are single-center experiences with a small number of patients; (2) there is no gold standard for PRES diagnosis because of the absence of a specific biomarker; (3) most studies are retrospectively using diagnostic inclusion criteria which conform to the earlier descriptions of the "typical" disorder, thereby excluding more atypical phenotypes. The boundaries of PRES are uncertain at this time, as the recent descriptions of "normal MRI" at onset and spinal cord involvement, suggest. ${ }^{1}$ Also what has become clear over time is that features like the presence of restricted diffusion, absence of posterior lesions as well as reversibility, and poor outcome are no longer exclusionary in the diagnosis of PRES.

What is needed is a large prospective study including all patients with acute neurologic symptoms in the presence of risk factors with compatible typical or atypical MRI features and with the reasonable exclusion of other diagnoses. ${ }^{1}$ This would define what are the outer limits of a diagnosis of PRES. As it is uncommon in children a multicenter collaboration would be needed.

\section{References}

1. Fugate JE, Rabinstein AA. Posterior reversible encephalopathy syndrome: Clinical and radiological manifestations, pathophysiology, and outstanding questions. Lancet Neurol 2015;14(9):914-925. DOI: 10.1016/S1474-4422(15)00111-8.

2. Chen TH. Childhood posterior reversible encephalopathy syndrome: Clinicoradiological characteristics, managements, and outcome. Front Pediatr 2020;8:585. DOI: 10.3389/fped.2020.00585.

3. Hinchey J, Chaves C, Appignani B, Breen J, Pao L, Wang A, et al. A reversible posterior leukoencephalopathy syndrome. N Engl J Med 1996;334(8):494-500. DOI: 10.1056/NEJM199602223340803.

4. Thavamani A, Umapathi KK, Puliyel M, Super D, Allareddy V, Ghori A, et al. Epidemiolog, comorbidities, and outcomes of posterior reversible encephalopathy syndrome in children in the United States. Pediatr Neurol 2020;103:21-26. DOI: 10.1016/j.pediatrneurol. 2019.07.007.

5. Raj S, Overby P, Erdfarb A, Ushay HM. Posterior reversible encephalopathy syndrome: incidence and associated factors in a pediatric critical care population. Pediatr Neurol 2013;49(5):335-339. DOI: 10.1016/j.pediatrneurol.2013.06.007.

6. Behera CK, Jain MK, Mishra R, Jena PK, Dash SK, Sahoo RK. Clinicoradiological profile of posterior reversible encephalopathy syndrome and its associated risk factors in PICU: A single-center experience from a tertiary care hospital in Bhubaneswar, Odisha. Indian J Crit Care Med 2020;24(12):1223-1229.

7. Mishra S, Kusuma YS, Babu BV. Treatment-seeking and out-of-pocket expenditure on childhood illness in a migrant tribal community in Bhubaneswar, Odisha state, India. Paediatr Int Child Health 2017;37(3):181-187. DOI: 10.1080/20469047.2016.1245031. 